\title{
Five fraction image-guided radiosurgery for primary and recurrent meningiomas
}

\author{
Eric Karl Oermann ${ }^{1,2 *}$, Rahul Bhandari ${ }^{1}$, Viola J. Chen ${ }^{2}$, Gabriel Lebec ${ }^{2}$, Marie Gurka ${ }^{2}$, Siyuan Lei ${ }^{2}$, \\ Leonard Chen ${ }^{1}$, Simeng Suy ${ }^{2}$, Norio Azumi ${ }^{3}$, Frank Berkowitz ${ }^{4}$, Christopher Kalhorn ${ }^{1}$, Kevin McGrail ${ }^{1}$, \\ Brian Timothy Collins ${ }^{2}$, Walter C. Jean ${ }^{1}$ and Sean P. Collins ${ }^{2 *}$
}

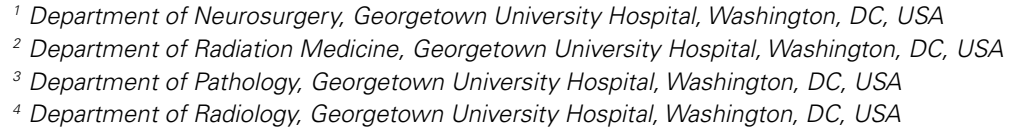

${ }^{1}$ Department of Neurosurgery, Georgetown University Hospital, Washington, DC, USA

${ }^{2}$ Department of Radiation Medicine, Georgetown University Hospital, Washington, DC, USA

${ }^{3}$ Department of Pathology, Georgetown University Hospital, Washington, DC, USA

${ }^{4}$ Department of Radiology, Georgetown University Hospital, Washington, DC, USA

\section{Edited by:}

Nam Phong Nguyen, International

Geriatric Radiotherapy Group, USA

Reviewed by:

Michael Chan, Wake Forest

University, USA

Christopher Schultz, Medical College

of Wisconsin, USA

*Correspondence:

Eric Karl Oermann and Sean P. Collins, Department of Radiation Medicine,

Georgetown University Medical

Center, 3800 Reservoir Road NW,

Washington, DC 20007, USA

e-mail: eko@georgetown.edu;

spc9@georgetown.edu
Purpose: Benign tumors that arise from the meninges can be difficult to treat due to their potentially large size and proximity to critical structures such as cranial nerves and sinuses. Single fraction radiosurgery may increase the risk of symptomatic peritumoral edema. In this study, we report our results on the efficacy and safety of five fraction image-guided radiosurgery for benign meningiomas.

Materials/Methods: Clinical and radiographic data from 38 patients treated with five fraction radiosurgery were reviewed retrospectively. Mean tumor volume was $3.83 \mathrm{~mm}^{3}$ (range, $1.08-20.79 \mathrm{~mm}^{3}$ ). Radiation was delivered using the CyberKnife, a frameless robotic image-guided radiosurgery system with a median total dose of 25 Gy (range, 25-35 Gy).

Results: The median follow-up was 20 months. Acute toxicity was minimal with eight patients $(21 \%)$ requiring a short course of steroids for headache at the end of treatment. Pre-treatment neurological symptoms were present in 24 patients (63.2\%). Post treatment, neurological symptoms resolved completely in 14 patients $(58.3 \%)$, and were persistent in eight patients (33.3\%). There were no local failures, 24 tumors remained stable (64\%) and 14 regressed (36\%). Pre-treatment peritumoral edema was observed in five patients (13.2\%). Post-treatment asymptomatic peritumoral edema developed in five additional patients (13.2\%). On multivariate analysis, pre-treatment peritumoral edema and location adjacent to a large vein were significant risk factors for radiographic post-treatment edema ( $p=0.001$ and $p=0.026$ respectively).

Conclusion: These results suggest that five fraction image-guided radiosurgery is well tolerated with a response rate for neurologic symptoms that is similar to other standard treatment options. Rates of peritumoral edema and new cranial nerve deficits following five fraction radiosurgery were low. Longer follow-up is required to validate the safety and long-term effectiveness of this treatment approach.

Keywords: radiosurgery, meningioma, toxicity, fractionation, treatment outcome

\section{BACKGROUND}

Meningiomas are commonly benign tumors with a generally favorable prognosis (1). However, without treatment they may progress locally, compressing adjacent structures and causing neurologic deficits. They pose a unique clinical challenge due to their large size and variable anatomical locations within the skull (1). Surgical resection of the entire tumor, when possible without neurologic injury, is the standard of care with a 10 -year local control of $80 \%$ or higher (2-9). For subtotally resected or recurrent tumors, conventionally fractionated radiation therapy (1.8-2.0 Gy per fraction) to approximately $54 \mathrm{~Gy}$ improves local control $(2,4,6-8)$.

More recent experience suggests a role for single fraction stereotactic radiosurgery (SRS) (12-18 Gy) as a primary treatment for well selected, small meningiomas or as adjuvant treatment for residual disease (10-12). In cases where single fraction SRS has been appropriately utilized, results have been excellent, demonstrating equivalent local control to both conventional radiation therapy and surgical resection for select groups of meningioma patients $(10,11)$. Patients with large tumors $(>7.5 \mathrm{cc})$ have a poor prognosis with this approach, and unacceptably high rates of local failure $(10,11)$.

Single fraction radiosurgery, however, may increase the risk of symptomatic peritumoral edema and/or cranial nerve injury $(10,12,13)$. This risk of peritumoral edema may be increased in tumors that are large, recurrent, adjacent to large veins, and/or basally located (10,13-19). Conventional fractionated radiation therapy has been employed to treat these patients. The gross tumor volume (GTV) is typically targeted with a margin of $2-5 \mathrm{~mm}$ to adjust for set-up inaccuracy. Due to these large planned treatment volumes (PTVs), treatment is generally fractionated over 25-30 
sessions to limit toxicity to adjacent normal structures. Due to the long natural history of this disease, it is essential to maximize posttreatment quality of life by preventing treatment related adverse outcomes while minimizing neurological symptoms associated with tumor progression. It is possible that some of the adverse effects of single fraction radiosurgery for large tumors may be mitigated by limited fractionation.

The CyberKnife is an image-guided, frameless, SRS platform. The frameless configuration allows for staged treatment, and it has been successfully utilized to treat a wide variety of intracranial tumors including meningiomas $(8,9,20)$. In this retrospective study, we report our preliminary results with five fraction image-guided radiosurgery as a treatment for meningiomas, either as monotherapy or as an adjuvant to surgical resection. This treatment was conducted with the belief that its accurate and highly conformal delivery would minimize peritumoral edema and cranial nerve toxicity.

\section{MATERIALS AND METHODS}

\section{PATIENT SELECTION AND TREATMENT}

We performed a retrospective review of patients with benign meningiomas treated with CyberKnife SRS from December 1st, 2007 to February 1st, 2011 by SPC and BTC. Patients who had undergone SRS for intracranial meningiomas with or without surgical resection were included in the present study. Patients with atypical or malignant meningiomas were excluded from this study. All patients were treated by an interdisciplinary team of radiation oncologists and neurosurgeons. High resolution CT images were obtained from all patients for pre-treatment planning with target volumes, and critical structures were manually delineated by the treating neurosurgeon (Figure 1). The treating isodose and prescription dose were determined by the treating radiation oncologist in consultation with the treating neurosurgeon, and took into account the target volume, proximity to critical structures, and previous treatment history. In most cases, the dose was prescribed to the isodose surface that encompassed the margin of the tumor. Treatment plans were generated using an inverse planning method by the CyberKnife treatment software (Multiplan, Accuray).

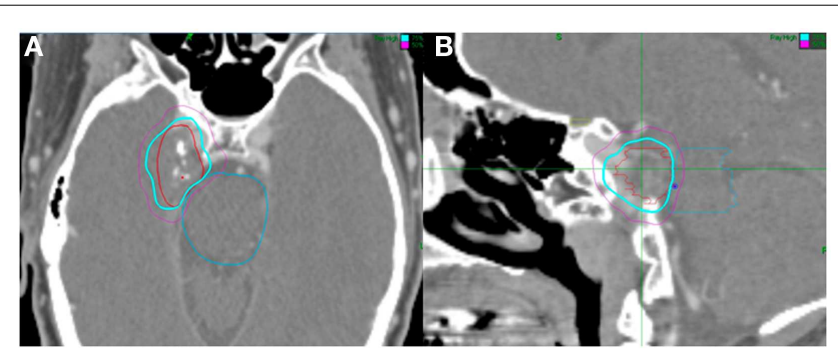

FIGURE 1 | Fifty-three-year-old man with a right Meckel cave meningioma. He presented with right facial pain. The decision was to proceed with radiosurgery. Treatment planning axial (A) and sagittal (B) computed tomography images demonstrating the GTV (red), brainstem (blue), and chiasm (yellow). Isodose lines shown as follows: blue $79 \%$ (prescription) and purple $50 \%$. Note proximity of the meningioma to the brainstem. The tumor was treated with 2500 cGy in five fractions and his pain resolved.

\section{OUTCOMES ASSESSMENT}

Patients were tracked as part of routine clinical follow-up by the interdisciplinary team. MRI scans were obtained at pre-defined intervals, every 6 months for the first year, and then yearly thereafter, unless acute changes in neurological status warranted immediate imaging. Neurological symptoms were clinically assessed and recorded by the treating neurosurgeons. Peritumoral edema was assessed on T2 weighted and FLAIR MRI sequences. Patient steroid requirements were assessed at each clinical follow-up visit.

\section{STATISTICAL ANALYSIS}

All statistical analyses were performed utilizing SPSS Statistics v19 (IBM). Statistical analysis was performed in order to identify pre-treatment and treatment variables that correlated with post-treatment peritumoral edema. Due to the relatively small sample size, Fisher's Exact Test was used for categorical variables, while Spearman's Rho was employed for examining the interaction between continuous variables and post-treatment peritumoral edema. For analysis of volume and dose, due to the small sample sizes, patients were stratified as being over or under the median and a Chi-square test was employed. Alpha was set to 0.05 to yield a $95 \%$ confidence interval (CI) for all statistical tests.

\section{RESULTS}

\section{PATIENT AND TREATMENT CHARACTERISTICS}

Thirty-eight patients were identified as having undergone treatment for intracranial meningiomas and were subsequently included in the current study (Table 1). Twenty-nine (79\%) of the patients were female and nine $(24 \%)$ were male. The median age at time of treatment with radiosurgery was 64 years. Thirteen (34\%) patients had undergone prior surgery, of which five were classified as gross total resection and eight were classified as subtotal resections. The remaining 24 patients had received no previous surgical or non-surgical interventions and were treated without pathologic confirmation. Twenty-seven $(71 \%)$ of the tumors were primary, while $11(29 \%)$ were recurrent. The tumors occurred

Table 1 | A summary of patient characteristics for patients included in the study.

\begin{tabular}{lrr}
\hline Characteristic & $\mathbf{N}=\mathbf{3 8}$ & (\%) \\
\hline Race/ethnicity & 24 & \\
Caucasian & 11 & $(63)$ \\
African American & 1 & $(29)$ \\
Hispanic & 2 & $(3)$ \\
Asian & & $(5)$ \\
Gender & 29 & \\
Female & 9 & $(76)$ \\
Male & & \\
Age at radiosurgery & 62 & \\
Mean & 64 & \\
Median & & \\
Extent of resection & 5 & $(13)$ \\
Gross total & 8 & $(63)$ \\
Subtotal & 24 & \\
No surgery & &
\end{tabular}


Table 2 | A summary of tumor characteristics for all tumors included within the study.

\begin{tabular}{|c|c|c|}
\hline Characteristic & $N=38$ & (\%) \\
\hline \multicolumn{3}{|l|}{ Primary vs. recurrent } \\
\hline Primary & 27 & $(71)$ \\
\hline Recurrent & 11 & (29) \\
\hline \multicolumn{3}{|l|}{ Location: general } \\
\hline Basal & 22 & (58) \\
\hline Non-basal & 16 & (42) \\
\hline \multicolumn{3}{|l|}{ Location: specific } \\
\hline Bifrontal & 1 & (3) \\
\hline Cavernous sinus & 7 & (18) \\
\hline Cerebellopontine angle & 5 & (13) \\
\hline Falcine & 2 & (5) \\
\hline Falcotentorial & 1 & (3) \\
\hline Lateral ventricle & 1 & (3) \\
\hline Meckel's cave & 2 & (5) \\
\hline Middle cranial fossa & 1 & (3) \\
\hline Parafalcine & 2 & (5) \\
\hline Parasagittal & 5 & (13) \\
\hline Parietal convexity & 1 & (3) \\
\hline Parietal lobe & 1 & (3) \\
\hline Petroclival & 2 & (5) \\
\hline Posterior fossa & 1 & (3) \\
\hline Sphenoid wing & 2 & (5) \\
\hline Suprasellar & 1 & (3) \\
\hline Temporal lobe & 3 & (8) \\
\hline \multicolumn{3}{|l|}{ Volume (cc) } \\
\hline Min & 1.08 & \\
\hline Max & 20.79 & \\
\hline Mean & 6.22 & \\
\hline Median & 3.84 & \\
\hline
\end{tabular}

at a variety of intracranial sites (Table 2), with an almost even number of basal and non-basal tumors, 22 (58\%) and 16 (42\%) respectively. The median tumor volume was $3.83 \mathrm{~mm}^{3}$ (range, $\left.1.08-20.79 \mathrm{~mm}^{3}\right)$. The median isodose was $82 \%(70-90 \%)$ which was treated with a median prescription dose of 2500 cGy (2500$3500 \mathrm{cGy})$ and resulted in a median percent tumor coverage of 99.5\% (Table 3).

\section{COMPLICATIONS AND NEUROLOGICAL SYMPTOMS AFTER SRS}

Acute toxicity after SRS treatment included symptoms such as headaches, fatigue, and nausea. Headaches were the most common complication with nine patients $(23.7 \%)$ complaining of headaches at the end of treatment. Four patients (10.5\%) experienced fatigue, and only one patient $(2.6 \%)$ complained of nausea. Twenty-four patients (63.2\%) presented with neurological symptoms prior to therapy (Table 4). These neurological symptoms included facial pain, hearing loss, diplopia, proptosis, vertigo, facial numbness, and reduced visual acuity. After SRS, neurological examination revealed complete resolution of neurological symptoms in 14 patients $(58.3 \%)$, continued symptoms in eight patients (33.3\%), and recurrence of symptoms after initial improvement in two patients $(8.3 \%)$. Only one patient $(2.6 \%)$ developed a
Table 3 | A summary of treatment characteristics for patients treated on a frameless stereotactic radiosurgical system.

\begin{tabular}{lclc}
\hline Characteristic & $\mathbf{N = 3 8}$ & Characteristic & $\mathbf{N = 3 8}$ \\
\hline Rx dose (cGy) & \multicolumn{3}{l}{ Percent tumor covered } \\
Min & 2500 & Min & 97.4 \\
Max & 3500 & Max & 99.9 \\
Mean & 2691 & Mean & 99.3 \\
Median & 2500 & Median & 99.5 \\
Isodose line (\%) & & Non-zero beams & \\
Min & 70 & Min & 88 \\
Max & 90 & Max & 259 \\
Mean & 82 & Mean & 175 \\
Median & 82 & Median & 174 \\
Homogeneity index & & Collimator (mm) & \\
Min & 1 & Min & 5 \\
Max & 1.39 & Max & 15 \\
Mean & 1.22 & Mean & 11 \\
Median & 1.2 & Median & \\
New conformality index & & & \\
Min & 1.32 & & \\
Max & 2.25 & \\
Mean & 1.66 & \\
Median & 1.61 & \\
& &
\end{tabular}

Table 4 | A summary of changes in neurological deficits.

\begin{tabular}{lcccc}
\hline Deficit & $\begin{array}{l}\text { Pre- } \\
\text { SRS }\end{array}$ & $\begin{array}{l}\text { Improved } \\
\text { post- } \\
\text { SRS }\end{array}$ & $\begin{array}{l}\text { Recurrence } \\
\text { after initial } \\
\text { improvement }\end{array}$ & $\begin{array}{l}\text { Continued } \\
\text { Sx } \\
\text { post-SRS }\end{array}$ \\
\hline Facial pain & 9 & 5 & 2 & 2 \\
Hearing loss & 1 & 0 & 0 & 1 \\
Diplopia & 4 & 4 & 0 & 0 \\
Proptosis & 2 & 0 & 0 & 2 \\
Vertigo & 2 & 2 & 0 & 0 \\
Facial numbness & 4 & 3 & 0 & 1 \\
Reduced visual acuity & 2 & 0 & 0 & 2 \\
\hline
\end{tabular}

All neurological deficits were noted by the treatment team on either clinical exam or through direct questioning of the patient.

new deficit, facial numbness, immediately after radiation, which resolved after a few days. Otherwise, no new neurological deficits were observed after SRS.

Facial pain was the most common presenting neurological symptom pre-SRS treatment. Of the nine patients $(37.5 \%)$ who presented with facial pain, five patients $(55.6 \%)$ were asymptomatic after radiation, two patients $(22.2 \%)$ had continued symptoms, and another two patients $(22.2 \%)$ had recurrent facial pain after initial improvement. Diplopia, vertigo, and facial numbness improved in the majority of patients. Proptosis and reduced visual acuity did not improve with treatment.

\section{LOCAL CONTROL RATE AND PERITUMORAL EDEMA}

Twenty-four patients $(63.2 \%)$ who underwent SRS showed no change in tumor size, while 14 patients $(36.8 \%)$ showed a decrease 
Table 5 | (A) A comprehensive table detailing individual patient outcomes with regards to pre-treatment therapies, radiation dosage, and subsequent clinical outcomes. (B) A summary of individual patient factors and whether patients had pre-treatment or post-treatment peritumoral edema.

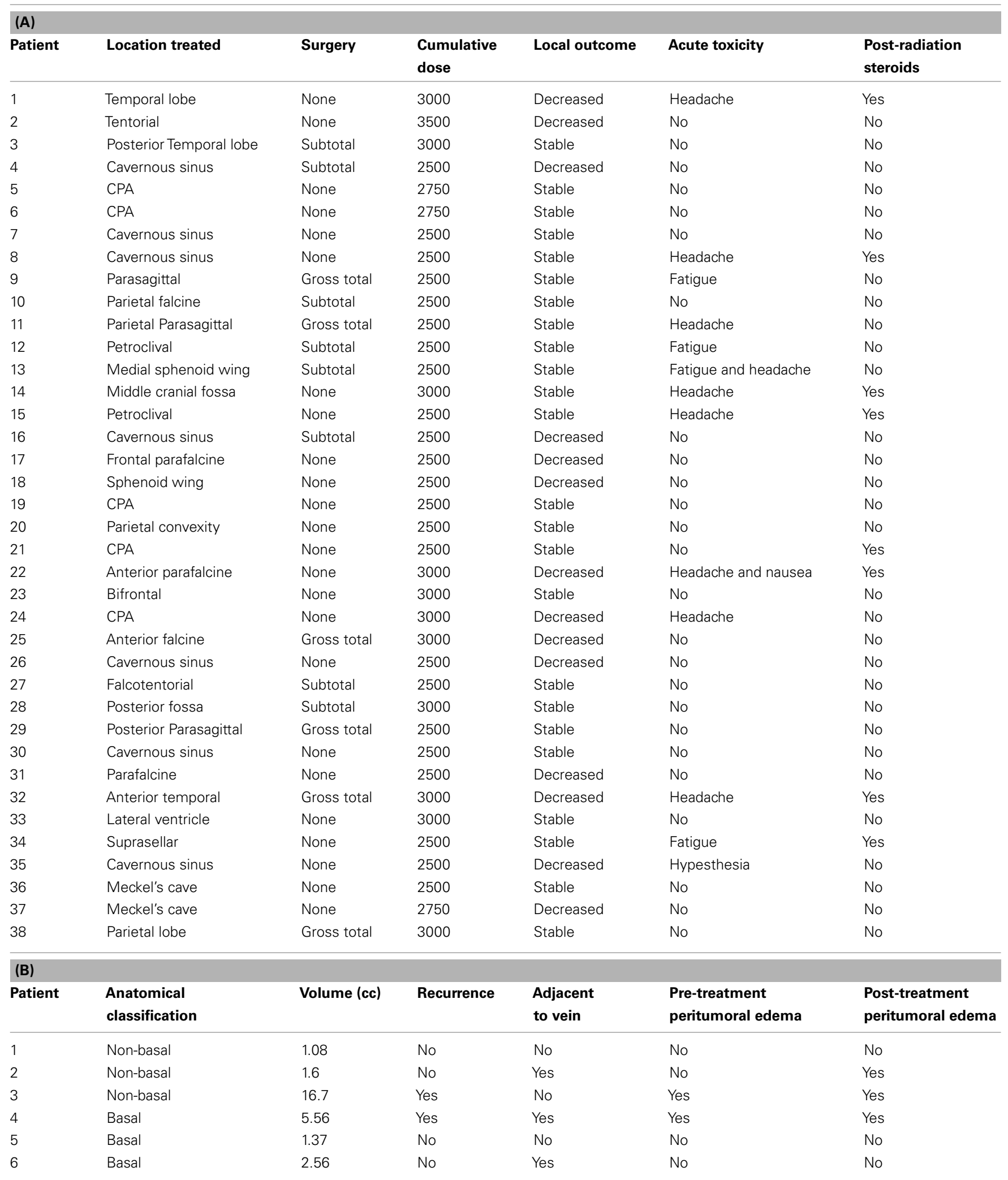


Table 5 | Continued

\begin{tabular}{|c|c|c|c|c|c|c|}
\hline Patient & $\begin{array}{l}\text { Anatomical } \\
\text { classification }\end{array}$ & Volume (cc) & Recurrence & $\begin{array}{l}\text { Adjacent } \\
\text { to vein }\end{array}$ & $\begin{array}{l}\text { Pre-treatment } \\
\text { peritumoral edema }\end{array}$ & $\begin{array}{l}\text { Post-treatment } \\
\text { peritumoral edema }\end{array}$ \\
\hline 7 & Basal & 4.05 & No & No & No & No \\
\hline 9 & Non-basal & 11.24 & Yes & No & Yes & Yes \\
\hline 10 & Non-basal & 6.48 & Yes & No & No & No \\
\hline 11 & Non-basal & 6.44 & Yes & Yes & No & No \\
\hline 13 & Basal & 20.17 & No & No & No & No \\
\hline 14 & Basal & 2.14 & No & Yes & No & Yes \\
\hline 15 & Basal & 20.79 & No & No & No & No \\
\hline 16 & Basal & 13.82 & No & Yes & Yes & Yes \\
\hline 17 & Non-basal & 6.43 & No & No & No & No \\
\hline 22 & Non-basal & 1.17 & No & No & No & No \\
\hline 23 & Non-basal & 6.59 & No & No & No & No \\
\hline 24 & Basal & 1.53 & No & No & No & No \\
\hline 25 & Non-basal & 3.59 & Yes & Yes & Yes & Yes \\
\hline 26 & Basal & 13.07 & No & No & No & No \\
\hline 27 & Non-basal & 4.68 & No & No & No & No \\
\hline 28 & Basal & 11.83 & Yes & No & No & No \\
\hline 29 & Non-basal & 2.63 & Yes & No & No & Yes \\
\hline 30 & Basal & 2.65 & No & No & No & No \\
\hline 31 & Non-basal & 2.611 & No & No & No & Yes \\
\hline 32 & Non-basal & 3.04 & Yes & Yes & No & No \\
\hline
\end{tabular}

Table 6 | A statistical analysis of variables associated with peritumoral edema.

\begin{tabular}{lll}
\hline Pre-treatment characteristic & Likelihood ratio & $\boldsymbol{p}$-Value \\
\hline Pre-treatment peritumoral edema & 15.77 & 0.001 \\
Anatomical classification & 1.28 & 0.293 \\
Adjacent to vein & 4.83 & 0.045 \\
Volume (cc) & 0 & 1 \\
Recurrence & 2.77 & 0.116 \\
Cumulative dose & 0.002 & 0.968 \\
\hline
\end{tabular}

p-Values are for two-sided Fisher's Exact Test.

in tumor size resulting in a crude radiographic local control rate of $100 \%$ of the meningiomas treated with SRS (Table 5).

Intracranial edema is commonly managed with oral steroids, and oral steroid requirements were measured as a surrogate for post-radiation peritumoral edema. Symptomatic, acute, post-radiation edema requiring steroids occurred in six patients
(15.8\%). In addition, two patients (5.3\%) were given steroids due to evidence of post-radiation edema on MRI, but without any clinical signs of toxicity (Table 5).

Pre-SRS radiographic peritumoral edema continued to be observed in five patients (13.2\%) on follow-up MRI imaging. Of these patients, four $(10.5 \%)$ had recurrent tumors following a subtotal or gross resection, and three $(7.9 \%)$ had a radiological tumor volume greater than $10.0 \mathrm{cc}$ (Table 5). A total of 10 patients had post-treatment radiographic peritumoral edema, with new onset being observed in five patients (13.2\%). On univariate statistical analysis, only pre-treatment peritumoral edema $(p=0.001)$ and adjacency to a large vein $(p=0.045)$ correlated with post-treatment peritumoral edema (Table 6).

\section{DISCUSSION}

Our results show that fractionated SRS may provide similar local control with minimal toxicity and excellent quality of life. Headaches, fatigue, and nausea were the only three acute complaints, all of which resolved over time. Headaches were the 
most common complication, present in $23.7 \%$ of our patients, which is consistent with other studies (12). Nausea was the least common, present in only one patient. This trend has also been observed in previous studies $(21,22)$.

In this study several patients presented with neurological symptoms and the majority responded to treatment with minimal toxicity at 2 years of follow-up. The present response rate of neurological symptoms compares favorably to similar studies with Gamma Knife $(17,21)$. Kondziolka et al. noted that five patients in their series of 99 cases had new or worsened deficits occurring 3-31 months after radiosurgery, while Chang et al. reported two cases out of 140 experiencing worsened deficits. Most tellingly, Kondziolka et al. reported that 67 out of 70 patients reported that their treatments were subjectively "successful" on an outcomes questionnaire, indicative of a high preservation of quality of life post-SRS (21). Uniquely, we have found an excellent response of tumor-associated facial pain to five fraction radiosurgery. While documented in other studies involving single fraction radiosurgery, our results suggest that a five fraction approach can also yield a beneficial reduction in tumor-associated trigeminal neuralgia (23-25). Other studies have suggested that recurrence of these symptoms typically occurs within 2 years, and is more likely to recur for malignant skull base tumors, with the mechanism of relief being decompression of affected nerve roots $(24,25)$.

Stereotactic radiosurgery was well tolerated with few posttreatment complications. As previously mentioned, other studies have suggested a relationship between tumor volume and post-SRS edema and complications (26). However, we found no correlation found between tumor volume, margin dose, and the presence of complications, which is similar to findings in other studies (12, 14, 22). Furthermore, it may be that if such a relationship does exist between large tumor volume and complications, that it may be mitigated in part through dose fractionation like in the present study.

At roughly 2 years, none of the patients developed local failures, and 14 showed a decrease in tumor size that may be correlated

\section{REFERENCES}

1. Alexiou GA, Gogou P, Markoula S, Kyritsis AP. Management of meningiomas. Clin Neurol Neurosurg (2010) 112:177-82. doi:10. 1016/j.clineuro.2009.12.011

2. Simpson D. The recurrence of intracranial meningiomas after surgical treatment. J Neurol Neurosurg Psychiatry (1957) 20:22-39. doi:10. 1136/jnnp.20.1.22

3. Mirimanoff RO, Dosoretz DE, Linggood RM, Ojemann RG, Martuza RL. Meningioma: analysis of recurrence and progression following neurosurgical resection. J Neurosurg (1985) 62:18-24. doi:10.3171/ jns.1985.62.1.0018

4. Barbaro NM, Gutin PH, Wilson CB, Sheline GE, Boldrey EB, Wara WM. Radiation therapy in the treatment of partially resected meningiomas. Neurosurgery (1987) 20:525-8. doi:10.1227/00006123-19870400000003
5. Condra KS, Buatti JM, Mendenhall WM, Friedman WA, Marcus RB Jr, Rhoton AL. Benign meningiomas: primary treatment selection affects survival. Int $J$ Radiat Oncol Biol Phys (1997) 39:427-36. doi:10.1016/S03603016(97)00317-9

6. Soyuer S, Chang EL, Selek U, Shi W, Maor MH, Demonte F. Radiotherapy after surgery for benign cerebral meningioma. Radiother Oncol (2004) 71:85-90. doi:10. 1016/j.radonc.2004.01.006

7. Rogers L, Mehta M. Role of radiation therapy in treating intracranial meningiomas. Neurosurg Focus (2007) 23:E4. doi:10.3171/FOC-07/ $10 / \mathrm{E} 4$

8. Colombo F, Casentini L, Cavedon C, Scalchi P, Cora S, Francescon P. Cyberknife radiosurgery for benign meningiomas: short-term results in 199 patients. Neurosurgery (2009) 64:A7-13.

favorably with local control, although this has not been conclusively shown (27). There is a high degree of variability in volume reduction post-radiosurgery with studies reporting rates less than $20 \%$ and over $60 \%$, ultimately the implications and the time course of post-radiosurgery volume reduction need to be further studied to ascertain its prognostic implications $(21,28)$. With regards to local control, control rates for meningiomas post-radiosurgery typically require longer follow-up for thorough assessment, with many studies placing the 10 -year rate of local control at $84 \%$ (11, 22, 29).

Only $13 \%$ of the patients developed new onset post-SRS peritumoral edema, with $26 \%$ of patients developing it overall. In addition, only $2.6 \%$ of the patient group receiving five fraction radiosurgery had symptomatic peritumoral edema. These results are in agreement with other papers on the use of hypofractionated radiosurgery for meningiomas, and compares favorably to an average of $5-10 \%$ of patients developing symptomatic edema in other studies $(12,21,30,31)$. In one such study by Kollova et al. edema was more common in tumor volumes greater than $10 \mathrm{~cm}^{3}$ (26). However the present study and others have suggested that simple tumor volume is not a significant contributor to post-radiation peritumoral edema, which may be in fact more due to the interface between meningioma and cortical tissue rather than gross volume $(21,32)$.

\section{CONCLUSION}

Stereotactic radiosurgery is a safe and effective treatment for benign intracranial meningiomas with or without surgical resection. Dose fractionation is well tolerated, and may offer equivalent local control to single session SRS. Fractionation may offer particular benefit to patients with large tumors located in critical locations or in other high-risk patients. Further studies are warranted to fully ascertain the potential benefits and risks of dose fractionation for SRS therapy of meningiomas, and its ultimate impact on local control.

doi:10.1227/01.NEU.0000338947. 84636.A6

9. Coppa ND, Raper DM, Zhang Y, Collins BT, Harter KW, Gagnon GJ, et al. Treatment of malignant tumors of the skull base with multi-session radiosurgery. J Hematol Oncol (2009) 2:16. doi:10.1186/ 1756-8722-2-16

10. Kondziolka D, Flickinger JC, Perez B. Judicious resection and/or radiosurgery for parasagittal meningiomas: outcomes from a multicenter review. Gamma Knife Meningioma Study Group. Neurosurgery (1998) 43:405-13; discussion 413-4. doi:10.1097/00006123-19980900000001

11. Pollock BE, Stafford SL, Utter A, Giannini C, Schreiner SA. Stereotactic radiosurgery provides equivalent tumor control to Simpson Grade 1 resection for patients with small- to medium-size meningiomas. Int $J$ Radiat Oncol Biol Phys (2003) 55:1000-5. doi:10. 1016/S0360-3016(02)04356-0

12. DiBiase SJ, Kwok Y, Yovino S, Arena C, Naqvi S, Temple R, et al. Factors predicting local tumor control after gamma knife stereotactic radiosurgery for benign intracranial meningiomas. Int $J$ Radiat Oncol Biol Phys (2004) 60:1515-9. doi:10.1016/j.ijrobp. 2004.05.073

13. Ganz JC, Schrottner O, Pendl G. Radiation-induced edema after Gamma Knife treatment for meningiomas. Stereotact Funct Neurosurg (1996) 66(Suppl 1):129-33. doi:10. 1159/000099778

14. Nakamura S, Hiyama H, Arai K, Nakaya K, Sato H, Hayashi M, et al. Gamma Knife radiosurgery for meningiomas: four cases of radiation-induced edema. Stereotact Funct Neurosurg (1996) 66(Suppl 1):142-5. doi:10.1159/000099804 
15. Vermeulen S, Young R, Li F, Meier $\mathrm{R}$, Raisis J, Klein S, et al. A comparison of single fraction radiosurgery tumor control and toxicity in the treatment of basal and nonbasal meningiomas. Stereotact Funct Neurosurg (1999) 72(Suppl 1): 60-6.

16. Singh VP, Kansai S, Vaishya S, Julka PK, Mehta VS. Early complications following gamma knife radiosurgery for intracranial meningiomas. J Neurosurg (2000) 93(Suppl 3):57-61.

17. Chang JH, Chang JW, Choi JY, Park YG, Chung SS. Complications after gamma knife radiosurgery for benign meningiomas. J Neurol Neurosurg Psychiatry (2003) 74:226-30. doi:10.1136/jnnp.74.2.226

18. Conti A, Pontoriero A, Salamone I, Siragusa C, Midili F, La Torre D, et al. Protecting venous structures during radiosurgery for parasagittal meningiomas. Neurosurg Focus (2009) 27:E11. doi:10.3171/2009.8. FOCUS09-157

19. Hasegawa T, Kida Y, Yoshimoto M, Iizuka $H$, Ishii $D$, Yoshida $K$. Gamma Knife surgery for convexity, parasagittal, and falcine meningiomas. J Neurosurg (2011) 114:1392-8. doi:10.3171/2010.11. JNS10112

20. Oermann E, Collins BT, Erickson KT, Yu X, Lei S, Suy S, et al. CyberKnife enhanced conventionally fractionated chemoradiation for high grade glioma in close proximity to critical structures. J Hematol Oncol (2010) 3:22. doi:10. 1186/1756-8722-3-22
21. Kondziolka D, Levy EI, Niranjan A, Flickinger JC, Lunsford LD. Long-term outcomes after meningioma radiosurgery: physician and patient perspectives. $J$ Neurosurg (1999) 91:44-50. doi:10.3171/jns.1999.91.1.0044

22. Stafford SL, Pollock BE, Foote RL, Link MJ, Gorman DA, Schomberg PJ, et al. Meningioma radiosurgery: tumor control, outcomes, and complications among 190 consecutive patients. Neurosurgery (2001) 49:1029-37; discussion 1037-28. doi:10.1097/00006123-20011100000001

23. Chang JW, Kim SH, Huh R, Park YG, Chung SS. The effects of stereotactic radiosurgery on secondary facial pain. Stereotact Funct Neurosurg (1999) 72(Suppl 1):29-37. doi:10.1159/000056436

24. Pollock BE, Iuliano BA, Foote RL, Gorman DA. Stereotactic radiosurgery for tumor-related trigeminal pain. Neurosurgery (2000) 46:576-82; discussion 582-3. doi:10.1097/00006123200003000-00010

25. Squire SE, Chan MD, Furr RM, Lowell DA, Tatter SB, Ellis TL, et al. Gamma knife radiosurgery in the treatment of tumor-related facial pain. Stereotact Funct Neurosurg (2012) 90:145-50. doi:10.1159/ 000335873

26. Kollova A, Liscak R, Novotny J Jr, Vladyka V, Simonova G, Janouskova L. Gamma Knife surgery for benign meningioma. J Neurosurg (2007) 107:325-36. doi:10.3171/ JNS-07/08/0325
27. Kondziolka D, Mathieu D, Lunsford LD, Martin JJ, Madhok R, Niranjan A, et al. Radiosurgery as definitive management of intracranial meningiomas. Neurosurgery (2008) 62:538; discussion 58-60. doi:10.1227/01. NEU.0000311061.72626.0D

28. Minniti G, Amichetti M, Enrici RM. Radiotherapy and radiosurgery for benign skull base meningiomas. Radiat Oncol (2009) 4:42. doi:10. 1186/1748-717X-4-42

29. Zada G, Pagnini PG, Yu C, Erickson KT, Hirschbein J, Zelman $\mathrm{V}$, et al. Long-term outcomes and patterns of tumor progression after gamma knife radiosurgery for benign meningiomas. Neurosurgery (2010) 67:322-8; discussion 328-29. doi:10.1227/01.NEU. 0000371974.88873.15

30. Santacroce A, Walier M, Regis J, Liscak R, Motti E, Lindquist C, et al. Long-term tumor control of benign intracranial meningiomas after radiosurgery in a series of 4565 patients. Neurosurgery (2012) 70:32-9; discussion 39. doi:10.1227/ NEU.0b013e31822d408a

31. Unger KR, Lominska CE, Chanyasulkit J, Randolph-Jackson P, White RL, Aulisi E, et al. Risk factors for posttreatment edema in patients treated with stereotactic radiosurgery for meningiomas. Neurosurgery (2012) 70:639-45. doi:10. 1227/NEU.0b013e3182351ae7

32. Cai R, Barnett GH, Novak E, Chao ST, Suh JH. Principal risk of peritumoral edema after stereotactic radiosurgery for intracranial meningioma is tumor-brain contact interface area. Neurosurgery (2010) 66:513-22. doi:10.1227/01. NEU.0000365366.53337.88

Conflict of Interest Statement: Brian Timothy Collins and Sean P. Collins have received honoraria from Accuray Inc. The other co-authors declare that the research was conducted in the absence of any commercial or financial relationships that could be construed as a potential conflict of interest.

Received: 23 June 2013; paper pending published: 17 July 2013; accepted: 03 August 2013; published online: 20 August 2013.

Citation: Oermann EK, Bhandari $R$, Chen VJ, Lebec G, Gurka M, Lei S, Chen L, Suy S, Azumi N, Berkowitz F, Kalhorn C, McGrail K, Collins BT, Jean WC and Collins SP (2013) Five fraction imageguided radiosurgery for primary and recurrent meningiomas. Front. Oncol. 3:213. doi: 10.3389/fonc.2013.00213

This article was submitted to Radiation Oncology, a section of the journal Frontiers in Oncology.

Copyright (C) 2013 Oermann, Bhandari, Chen, Lebec, Gurka, Lei, Chen, Suy, Azumi, Berkowitz, Kalhorn, McGrail, Collins, Jean and Collins. This is an openaccess article distributed under the terms of the Creative Commons Attribution License (CC BY). The use, distribution or reproduction in other forums is permitted, provided the original author (s) or licensor are credited and that the original publication in this journal is cited, in accordance with accepted academic practice. No use, distribution or reproduction is permitted which does not comply with these terms. 